\title{
Measurement and Decomposition of Consumption Inequality in Pakistan
}

\section{Muhammad Idrees* and Eatzaz Ahmad $^{* *}$}

\begin{abstract}
This paper shows that inequality in consumption expenditure in Pakistan improved slightly between 1992/93 and 2004/05, and that the extent of inequality in food consumption has remained substantially lower than in nonfood consumption. An important result is that household expenditure on education has been more unequally distributed than overall consumption expenditures. In contrast, healthcare expenditure in urban areas has been distributed relatively more evenly in recent years, while the level of inequality in healthcare expenditures in rural areas has remained persistent and somewhat higher.
\end{abstract}

Keywords: Consumption inequality, decomposition, Gini coefficient, Pakistan.

JEL Classification: D6, I3, D63, D31.

\section{Introduction}

Income inequality is one of the major economic problems that Pakistan faces. Despite the reasonable economic growth that Pakistan has achieved since its independence in 1947, poverty remains widespread, which is often attributed to the unequal distribution of income. Many studies have analyzed income inequality in Pakistan but only a few have focused on the decomposition of income inequality by household, sources of income, and other relevant attributes. Some significant contributions in this regard are Kurijk et al. (1985, 1986, and 1987), who carry out the decomposition of income inequality with respect to various factors such as regions, number of earners, labor and nonlabor income, and income sources. Adams (1993) analyzes the contribution of different sources of rural income to total income inequality in rural Pakistan. Nasir and Mahmood (1998) decompose inequalities of personal earnings with respect to the age of earners.

* Assistant Professor, Department of Economics, Quaid-i-Azam University, Islamabad, Pakistan.

** Professor, Department of Economics, Quaid-i-Azam University, Islamabad, Pakistan. 
However, hardly any study focuses on the measurement of consumption inequality and its decomposition into various components to see how overall inequality translates into inequality within each consumption component. It would be useful to compare inequality in consumption with the inequality within each subcategory of consumption, such as food, housing, and health, among others. Such an analysis would indicate the extent to which the overall inequality in consumption translates into inequality in essential indicators of wellbeing such as food consumption, housing expenditure, expenditure on health, expenditure on education, and others. This information would in turn be useful in understanding the various implications of inequality, such as the impact on investment in human capital through education and health. Another reason for undertaking this study is that inequality measures based on income alone are more likely to be biased due to business cycles and the misreporting of income as compared to income inequality measures that also consider consumption expenditure.

In addition, consumption is generally considered a more appropriate measure of well-being than income, especially in poor countries where the main concern is the fulfillment of basic needs. In this context, it is important to measure inequality in the distribution of disaggregated consumption including food, housing, and health.

The present study attempts to accomplish this task. The study is based on household-level consumption expenditure data for the survey years 1992/93, 1998/99, and 2004/05 taken from various issues of the Household Integrated Economic Survey (HIES). The analysis is carried out for Pakistan and its rural and urban areas. The measurement of inequality used is the Gini index and the unit of analysis is adultequivalent. ${ }^{1}$

The remaining paper is organized as follows: Section 2 describes the measurement of inequality and decomposition techniques. Sections 3 and 4 discuss the data used and results reported, respectively, and Section 5 concludes the study.

\footnotetext{
${ }^{1}$ Adult-equivalent works out the number of male adult-equivalents in a household. Each household member is expressed as a fraction of an adult male. Many adult-equivalent scales are proposed in the literature (see Elteto \& Havasi, 2002; Jafri, 2002; and Demoussis \& Mihalopoulos, 2001). The present study is based on the adult-equivalent scale proposed by Jafri $(1995,1999)$.
} 


\section{Measurement and Decomposition of Inequality}

The literature on techniques of measuring inequality has produced a wide variety of inequality measures. Obviously, not all measures are equally good in theory and practice. An inequality measure that is regarded as a good inequality measure usually has the following properties: (i) the Pigou-Dalton transfer principle, (ii) income scale independence, (iii) the population principle, (iv) decomposability, (v) well defined and interpretable limits, and (vi) symmetry. ${ }^{2}$

The Gini coefficient is one measure that fulfills all these conditions and is the most widely used measure of inequality. In our analysis, we use the Gini coefficient as a measure of inequality because it is sourcedecomposable and provides a neat interpretation. It lies between 0 and 1 , 0 representing perfect equality and 1 representing perfect inequality, and these well defined limits make it a relative measure, so that the values of the Gini coefficient for two different populations can also be compared. However, a problem associated with the Gini coefficient is that it gives more weight to income transfers affecting middle-income classes and not much weight to income transfers within extreme income classes. ${ }^{3}$

There are many approaches to defining the Gini coefficient, the most common being 'geometric approach,' in which the Gini coefficient is the ratio of the area between the line of absolute equality and the Lorenz curve to the total area below the line of absolute equality. Rao (1969) provides the following formula based on a geometric approach to calculating the Gini coefficient, which can also be used to measure inequality in consumption.

$$
G=\sum_{i=1}^{n-1}\left(P_{i} q_{i+1}-P_{i+1} q_{i}\right)
$$

Where $P_{i}$ is the cumulative population share and $q_{i}$ is the cumulative consumption share corresponding to the ith household when all households are arranged in ascending order of consumption.

\footnotetext{
${ }^{2}$ For more detail, see Idrees (2007) and Litchfield (1997).

${ }^{3}$ The Gini coefficient is income scale-independent but changes if a constant is added to all observations. This may turn out to be a problem if equality of life expectancy over time between geographical areas is to be measured. In this case, if the baseline increases in life expectancy of the overall population (it is, in effect, adding a constant), there can be a change in the Gini coefficient over time even if the absolute differences in life expectancy between the areas remains constant.
} 
Shorrocks (1982) provides the following source-decomposition of the Gini coefficient of income. The same procedure can be adopted for the allocation-wise decomposition of consumption inequality.

$$
G=\sum_{k=1}^{K}\left[s_{k}\left(C_{k}\right)\right]
$$

Here $s_{k}$ is the consumption share of the component $k$ in total consumption and $C_{k}$ is the concentration ratio of the $k t h$ consumption component. The concentration ratio is the same as that of the Gini coefficient except that the ranking of households is by total consumption and not the $k t h$ consumption component. This is given as:

$$
C_{k}=\sum_{i=1}^{n-1}\left(P_{i} q_{i+1}^{k}-P_{i+1} q_{i}^{k}\right)
$$

Where $P_{i}$ is the $i t h$ household's cumulative population share and $q_{i}^{k}$ is its cumulative share of the consumption component $k$. The concentration ratio of a particular consumption component measures how evenly or unevenly it is distributed as compared to the distribution of total consumption. If $C_{k}$ is greater (smaller) than the Gini coefficient, it implies that the consumption of $k$ th component is distributed more (less) unevenly than total consumption expenditure.

\section{Data Source and Period of Analysis}

The main source of data on household economic activity in Pakistan is the HIES, compiled and published by the Federal Bureau of Statistics, Government of Pakistan. It is a countrywide survey based on more than 14,000 households and provides fairly detailed information on consumption expenditures. HIES data is available in two formats, i.e. as aggregated data and disaggregated data. Information provided as aggregated data is with respect to entire groups of households classified as various income groups, e.g., the number of households in a group, average number of persons per household in a group, average monthly consumption per household in a group, and so on. This grouping suppresses important information and makes it impossible to explore consumption inequalities within households in the same group. Due to these limitations, the present study is based on disaggregated micro-level data, which provides detailed grassroots-level information on each 
household and its members. The study covers the survey years 1992/93, 1998/99 and 2004/05.4

For the decomposition of consumption inequality, two classifications of total household consumption are considered:

1. Decomposition of household consumption inequality into food and nonfood consumption components.

2. Decomposition of household consumption inequality into the following expenditure groups:

Group 1: Cereals and grains (all cereal products and food grains).

Group 2: Other food items (baked and fried products, milk and milk products, edible oils and fats, meat and fish, poultry, fresh and dry fruits, vegetables, condiments and spices, sugar, honey, tea and coffee, beverages, tobacco, chewing products, readymade food and other food items).

Group 3: Apparel textile, footwear and personal effects (clothing, footwear and items such as umbrellas, walking sticks, watches, etc, including repair and service charges of such articles).

Group 4: Household textiles (items such as pillow covers, bed sheets, quilts, blankets, curtains, table cloths, etc.).

Group 5: Fuel and lightning (electricity, gas, kerosene oil, firewood, coal, matchboxes, candles, etc.).

Group 6: House rent and housing expenses (rent paid by the household or rental value of owner-occupied house and expenses incurred by minor repairs and redecoration, etc.).

Group 7: Fixture and furniture and other durable household items (furniture, sanitary fittings, carpets, rugs, air conditioners, geysers, and knitting machines, etc.).

${ }^{4}$ Survey data is also available for 1996/97 and 2001/02, but these two years are not included in our analysis. Data for the survey year 2001/02 has been excluded from the analysis because it was made public after much controversy regarding the government's claims of the extent of poverty. Data for the year 1996/97 is also excluded from the analysis to create an equal time gap between the years of analysis. Apart from the above mentioned controversy, HIES data is considered fairly comprehensive and reliable in academic research. This is indicated by academic papers published around the world (see Kakwani, 2003, and Deaton, 1997). 
Group 8: Transport, travel, and communication (noncommercial transport, telephone, telegraph, postal charges, registration fee, driving license fee, and maintenance costs, etc.).

Group 9: Recreation and entertainment (tickets for cinemas, musical concerts, camera film, magazines, novels, storybooks, membership fees of social and recreational societies, license fee of noncommercial television, expenditure on hobbies, etc.).

Group 10: Education and professional expenditures (fees of educational institutions, private tuition fees, hostel living charges, expenditure on educational books, stationary, electronic equipment such as personal computers, membership fees of professional societies, etc.).

Group 11: Medical expenses (expenditure on medicines, contact lenses, hospitalization, doctor consultancy fees, etc.).

Group 12: Cleaning laundry and personal appearance (laundry, laundry articles, personal care articles and services, toilet rolls, soap, toothpaste, shampoo, hair cutting, dyeing, cosmetics, etc.).

Group 13: Miscellaneous (all remaining expenditure items such as legal expenses, locker charges, pocket money to children, fines, wages paid to household servants, religious and other occasional functions such as birthdays, marriages, etc.).

\section{Results and Discussion}

Estimates of overall household consumption inequality along with the decomposition results of consumption inequality in terms of food and nonfood consumption are shown in Table 1 . The table shows that the extent of inequality has declined moderately over the 12-year period considered and that this decline has been slightly greater in urban Pakistan than in rural Pakistan. Furthermore, the rate of decrease in the Gini coefficient during the last six years of analysis was greater than that during the initial six years. In rural Pakistan the extent of inequality increased slightly during the first six years. The period 1992/93 to $1989 / 99$ is typically regarded as a period of structural adjustment and economic squeeze in Pakistan. Thus, the slight increase in rural inequality can likely be attributed to cuts in subsidies on agricultural inputs and decreases in government development expenditure. 
We now consider the results of the decomposition of consumption inequality into food and nonfood components. This decomposition provides a broad picture of the incidence of inequality in terms of food and nonfood expenditure. For a more detailed analysis, we shall then decompose consumption inequality into 13 categories of food and nonfood consumption.

Table-1 also reports the decomposition of overall household consumption inequality into inequality in food and nonfood consumption. The results show that the concentration ratio in food is consistently lower than the corresponding Gini coefficient, while the concentration ratio in nonfood consumption expenditure is greater. This indicates that consumption inequality within food expenditures is lower than the inequality in nonfood expenditures. This expected result complies with the well-known Engle law that the share of food in total expenditure is greater among poor households than rich households, i.e., food is a relative necessity compared to nonfood consumption. The results show that the concentration ratio of nonfood consumption is nearly twice as large as that of food in urban Pakistan and more than 1.5 times as large in rural Pakistan, indicating that the incidence of inequality is mainly in nonfood consumption. This result also has important implications for poverty research. The typical practice in Pakistan is to compute food expenditure to meet the subsistence calorie requirement and divide the resulting figure by the share of food in income among those households that fall below the food poverty line (see Havinga et al. 1989). Since the share of food among poor households is relatively high, the poverty line of income is underestimated. This, in turn, underestimates various measures of poverty.

As far as contribution to overall consumption inequality is concerned, in all the three periods of analysis, nonfood consumption contributed more than $65 \%$ to overall consumption inequality in Pakistan, more than $71 \%$ in urban Pakistan, and more than 52\% in rural Pakistan. An interesting finding is that the share of food consumption in overall consumption expenditures has increased over time in both rural and urban Pakistan. This result is somewhat surprising, given that living standards, as measured by per capita consumption, have on average improved over the years both in rural and urban Pakistan. A possible reason is the popularity of more expensive foods in the form of packed products, imported and western-style foods that use expensive ingredients, such as fast food. Another reason could be the relatively higher rate of food inflation. 
Table-1: Decomposition of Overall Household Consumption Inequality into Food and Nonfood Categories

\begin{tabular}{|c|c|c|c|c|c|c|c|c|c|}
\hline \multirow{2}{*}{$\begin{array}{l}\text { Consumption } \\
\text { Groups \& } \\
\text { Inequality }\end{array}$} & \multicolumn{3}{|c|}{ 1992-93 } & \multicolumn{3}{|c|}{ 1998-99 } & \multicolumn{3}{|c|}{ 2004-05 } \\
\hline & Overall & Rural & Urban & Overall & Rural & Urban & Overall & Rural & Urban \\
\hline $\begin{array}{l}\text { Gini Index of } \\
\text { Consumption }\end{array}$ & 0.390 & 0.322 & 0.426 & 0.376 & 0.323 & 0.404 & 0.344 & 0.289 & 0.367 \\
\hline $\begin{array}{l}\text { Concentration } \\
\text { Ratio }\end{array}$ & 0.276 & 0.274 & 0.268 & 0.279 & 0.286 & 0.270 & 0.254 & 0.251 & 0.261 \\
\hline $\begin{array}{l}\text { Contribution to } \\
\text { Consumption } \\
\text { Expenditure (\%) }\end{array}$ & 44.10 & 50.55 & 37.78 & 46.47 & 53.80 & 38.76 & 47.10 & 54.32 & 40.00 \\
\hline $\begin{array}{l}\text { Contribution to } \\
\text { Gini Coefficient } \\
(\%)\end{array}$ & 31.19 & 42.95 & 23.75 & 34.46 & 47.46 & 25.89 & 34.84 & 47.24 & 28.48 \\
\hline \multicolumn{10}{|l|}{ Nonfood } \\
\hline $\begin{array}{l}\text { Concentration } \\
\text { Ratio }\end{array}$ & 0.480 & 0.372 & 0.522 & 0.461 & 0.366 & 0.488 & 0.423 & 0.333 & 0.437 \\
\hline $\begin{array}{l}\text { Contribution to } \\
\text { Consumption } \\
\text { Expenditure (\%) }\end{array}$ & 55.90 & 49.45 & 62.22 & 53.53 & 46.20 & 61.24 & 52.90 & 45.68 & 60.00 \\
\hline $\begin{array}{l}\text { Contribution to } \\
\text { Gini Coefficient } \\
(\%)\end{array}$ & 68.81 & 57.05 & 76.25 & 65.54 & 52.54 & 74.11 & 65.16 & 52.76 & 71.52 \\
\hline
\end{tabular}

We now split inequality in consumption expenditure into the major components of food and especially nonfood consumption. For this, we divide food consumption into two categories and nonfood consumption into 11 categories. The results of decomposition are shown in Table-2. The table also reports the share of each consumption category in total household consumption expenditure. According to the results, more than $58 \%$ of total consumption expenditure is incurred by two food groups and the category 'house rent and housing expenses.' These three categories obviously represent the most important consumption requirements of households.

The decomposition results in the table show that, throughout the period of analysis, the concentration ratios of four groups (cereals and grains; other food items; apparel textile, footwear, and personal effects; and fuel and lightning have remained lower than the overall Gini coefficients of household consumption. This implies that the effect of inequality in consumption is disproportionately less in these consumption categories. Therefore, the consumption share of these 
categories among poor households remained greater than the consumption share among rich households. It also follows, therefore, that these consumption components are classified as relative necessities.

Table-2: Decomposition of Overall Household Consumption Inequality into Major Consumption Groups

\begin{tabular}{|c|c|c|c|c|c|c|c|c|c|}
\hline \multirow{2}{*}{$\begin{array}{l}\text { Consumption } \\
\text { Components and } \\
\text { Inequality }\end{array}$} & \multicolumn{3}{|c|}{$1992-93$} & \multicolumn{3}{|c|}{ 1998-99 } & \multicolumn{3}{|c|}{ 2004-05 } \\
\hline & Overall & Rural & Urban & Overall & Rural & Urban & Overall & Rural & Urban \\
\hline \multicolumn{10}{|l|}{ Cereals and grains } \\
\hline Concentration Ratio & 0.184 & 0.213 & 0.155 & 0.199 & 0.249 & 0.157 & 0.151 & 0.193 & 0.120 \\
\hline $\begin{array}{l}\text { Contribution to } \\
\text { Consumption } \\
\text { Expenditure (\%) }\end{array}$ & 10.48 & 13.22 & 7.83 & 11.08 & 14.68 & 7.31 & 10.46 & 13.41 & 7.56 \\
\hline $\begin{array}{l}\text { Contribution to } \\
\text { Gini Coefficient (\%) }\end{array}$ & 4.94 & 8.73 & 2.85 & 5.86 & 11.32 & 2.85 & 4.59 & 8.97 & 2.47 \\
\hline \multicolumn{10}{|l|}{ Other food items } \\
\hline Concentration Ratio & 0.305 & 0.296 & 0.297 & 0.304 & 0.300 & 0.296 & 0.284 & 0.270 & 0.294 \\
\hline $\begin{array}{l}\text { Contribution to } \\
\text { Consumption } \\
\text { Expenditure (\%) }\end{array}$ & 33.58 & 37.33 & 29.95 & 35.38 & 39.12 & 31.45 & 36.64 & 40.91 & 32.44 \\
\hline $\begin{array}{l}\text { Contribution to } \\
\text { Gini Coefficient (\%) }\end{array}$ & 26.25 & 34.24 & 20.91 & 28.62 & 36.33 & 23.05 & 30.26 & 38.27 & 26.02 \\
\hline \multicolumn{10}{|c|}{ Apparel textile, footwear, and personal effects } \\
\hline Concentration Ratio & 0.335 & 0.286 & 0.375 & 0.307 & 0.292 & 0.329 & 0.298 & 0.268 & 0.317 \\
\hline $\begin{array}{l}\text { Contribution to } \\
\text { Consumption } \\
\text { Expenditure (\%) }\end{array}$ & 7.82 & 8.43 & 7.24 & 7.30 & 8.26 & 6.28 & 5.91 & 6.41 & 5.41 \\
\hline $\begin{array}{l}\text { Contribution to } \\
\text { Gini Coefficient (\%) }\end{array}$ & 6.72 & 7.48 & 6.37 & 5.96 & 7.46 & 5.12 & 5.11 & 5.95 & 4.69 \\
\hline \multicolumn{10}{|l|}{ Household textiles } \\
\hline Concentration Ratio & 0.475 & 0.408 & 0.511 & 0.383 & 0.377 & 0.400 & 0.369 & 0.323 & 0.423 \\
\hline $\begin{array}{l}\text { Contribution to } \\
\text { Consumption } \\
\text { Expenditure (\%) }\end{array}$ & 0.76 & 0.75 & 0.77 & 0.41 & 0.47 & 0.35 & 0.45 & 0.49 & 0.41 \\
\hline $\begin{array}{l}\text { Contribution to } \\
\text { Gini Coefficient (\%) }\end{array}$ & 0.93 & 0.95 & 0.92 & 0.42 & 0.55 & 0.35 & 0.48 & 0.55 & 0.47 \\
\hline \multicolumn{10}{|l|}{ Fuel and lightning } \\
\hline Concentration Ratio & 0.276 & 0.267 & 0.248 & 0.311 & 0.286 & 0.301 & 0.281 & 0.237 & 0.291 \\
\hline $\begin{array}{l}\text { Contribution to } \\
\text { Consumption } \\
\text { Expenditure (\%) }\end{array}$ & 5.15 & 5.47 & 4.84 & 6.14 & 6.26 & 6.01 & 7.63 & 7.76 & 7.51 \\
\hline
\end{tabular}


Contribution to

Gini Coefficient (\%)

$3.64 \quad 4.53$

House rent and housing expenses

Concentration Ratio $\quad 0.481 \quad 0.28$

Contribution to

Consumption $\begin{array}{llll}16.64 & 12.40 & 20.73 & 14.63\end{array}$

Expenditure (\%)

Contribution to

Gini Coefficient (\%) 20

Fixture and furniture

Concentration Ration
Contribution to

Consumption

Expenditure (\%)

Contribution to

Gini Coefficient (\%)

(16.64.

82

.

Transport traveling and communication

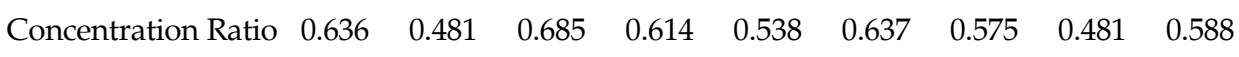

Contribution to

$\begin{array}{llllllllll}\text { Consumption } & 5.03 & 3.65 & 6.37 & 3.66 & 3.05 & 4.30 & 7.29 & 5.81 & 8.75\end{array}$

Expenditure (\%)

Contribution to

Gini Coefficient (\%)

$\begin{array}{lllllllll}8.19 & 5.44 & 10.23 & 5.97 & 5.08 & 6.79 & 12.19 & 9.68 & 14.04\end{array}$

Recreation and entertainment

\begin{tabular}{|c|c|c|c|c|c|c|c|c|c|}
\hline Concentration Ratio & 0.712 & 0.620 & 0.664 & 0.784 & 0.732 & 0.720 & 0.350 & 0.259 & 0.372 \\
\hline $\begin{array}{l}\text { Contribution to } \\
\text { Consumption } \\
\text { Expenditure (\%) }\end{array}$ & 0.91 & 0.49 & 1.32 & 1.54 & 0.61 & 2.52 & 1.70 & 1.56 & 1.85 \\
\hline $\begin{array}{l}\text { Contribution to } \\
\text { Gini Coefficient (\%) }\end{array}$ & 1.66 & 0.94 & 2.06 & 3.21 & 1.39 & 4.50 & 1.74 & 1.40 & 1.88 \\
\hline \multicolumn{10}{|c|}{ Education and professional expenditures } \\
\hline Concentration Ratio & 0.728 & 0.653 & 0.677 & 0.612 & 0.527 & 0.566 & 0.622 & 0.561 & 0.567 \\
\hline $\begin{array}{l}\text { Contribution to } \\
\text { Consumption } \\
\text { Expenditure (\%) }\end{array}$ & 2.23 & 1.16 & 3.26 & 3.69 & 2.19 & 5.26 & 2.95 & 1.87 & 4.01 \\
\hline $\begin{array}{l}\text { Contribution to } \\
\text { Gini Coefficient (\%) }\end{array}$ & 4.16 & 2.36 & 5.18 & 6.00 & 3.57 & 7.38 & 5.33 & 3.63 & 6.20 \\
\hline \multicolumn{10}{|l|}{ Medical expenses } \\
\hline Concentration Ratio & 0.399 & 0.354 & 0.457 & 0.370 & 0.368 & 0.388 & 0.318 & 0.333 & 0.294 \\
\hline $\begin{array}{l}\text { Contribution to } \\
\text { Consumption } \\
\text { Expenditure (\%) }\end{array}$ & 2.98 & 3.33 & 2.63 & 4.07 & 4.73 & 3.37 & 3.68 & 4.20 & 3.16 \\
\hline
\end{tabular}




\begin{tabular}{|c|c|c|c|c|c|c|c|c|c|}
\hline $\begin{array}{l}\text { Contribution to } \\
\text { Gini Coefficient (\%) }\end{array}$ & 3.04 & 3.66 & 2.83 & 4.00 & 5.39 & 3.24 & 3.41 & 4.86 & 2.54 \\
\hline \multicolumn{10}{|c|}{ Cleaning, laundry, and personal appearance } \\
\hline Concentration Ratio & 0.336 & 0.263 & 0.350 & 0.297 & 0.254 & 0.311 & 0.356 & 0.270 & 0.374 \\
\hline $\begin{array}{l}\text { Contribution to } \\
\text { Consumption } \\
\text { Expenditure (\%) }\end{array}$ & 4.17 & 4.05 & 4.29 & 3.75 & 3.87 & 3.61 & 2.37 & 2.16 & 2.58 \\
\hline $\begin{array}{l}\text { Contribution to } \\
\text { Gini Coefficient (\%) }\end{array}$ & 3.59 & 3.31 & 3.52 & 2.96 & 3.05 & 2.79 & 2.46 & 2.02 & 2.64 \\
\hline \multicolumn{10}{|l|}{ Miscellaneous } \\
\hline Concentration Ratio & 0.621 & 0.576 & 0.647 & 0.526 & 0.458 & 0.574 & 0.406 & 0.391 & 0.433 \\
\hline $\begin{array}{l}\text { Contribution to } \\
\text { Consumption } \\
\text { Expenditure (\%) }\end{array}$ & 8.83 & 8.52 & 9.12 & 7.58 & 7.21 & 7.96 & 6.22 & 6.91 & 5.55 \\
\hline $\begin{array}{l}\text { Contribution to } \\
\text { Gini Coefficient (\%) }\end{array}$ & 14.04 & 15.23 & 13.85 & 10.60 & 10.21 & 11.32 & 7.36 & 9.37 & 6.56 \\
\hline $\begin{array}{l}\text { verall Gini Index } \\
\text { f Consumption } \\
\text { nequality }\end{array}$ & 0.390 & 0.322 & 0.426 & 0.376 & 0.323 & 0.404 & 0.344 & 0.289 & 0.367 \\
\hline
\end{tabular}

House rent and housing expenses; fixtures and furniture; transport, travel, and communication; education and professional expenditures; and miscellaneous expenditure are the consumption groups whose concentration ratios have been greater than the overall Gini coefficients of household consumption throughout the period of analysis. This implies that rich households spend a relatively greater proportion of their expenditures on these consumption groups, so in general these can be treated as relative luxuries. The fact that the concentration ratio of educational and professional expenditures remained significantly greater than the Gini coefficients of aggregate consumption implies that inequality has a disproportionately adverse effect on expenditure on education among the poor. In other words, existing inequality has undesirable consequences on human capital formation among the poor. If all other things remain constant, this result implies that poverty is likely to be perpetuated among poor families.

In contrast to education, expenditure on healthcare is distributed more evenly compared to overall consumption expenditure, except for the first year of analysis, and the extent of inequality has declined over the years. This result is encouraging as it indicates that poor households are becoming more conscious of the health of their members and tend to consider healthcare a necessity relative to rest of the consumption basket. The results 
further show that expenditure on household textiles has been distributed more unequally than overall household consumption expenditure.

We now look at the consumption share of various consumption components in Pakistan overall. The statistics in Table 2 indicate that the combined share of the five consumption categories with a concentration ratio greater than the overall Gini coefficient of consumption fluctuated between approximately $22 \%$ and $41 \%$. These consumption categories make up the main incidence of inequality in consumption, while the remaining eight categories comprising $59 \%$ to $78 \%$ of consumption expenditure are somewhat insulated from the incidence of consumption inequality.

Not all categories of household consumption have experienced the same magnitude or even the same direction of change in inequality. The main reasons for the changing patterns of inequality in various consumption categories include the government's evolving economic stabilization policies, especially transfer payments (such as the people's work program and different employment schemes) and the changing nature of developmental expenditures. Inequality in food items, for example, is likely to have increased mainly due to higher indirect taxes relative to direct taxes, higher food inflation, and inconsistent economic growth. Likewise, the increase in inequality in fuel and lighting and transport can be attributed to substantial increases in the price of fuel items that are generally found to be necessities with low income elasticities.

On the other hand, the decrease in the concentration ratio of apparel could be because of a decrease in the relative prices of clothing items (that is, the prices of clothing items have grown less than the overall inflation rate during the period of analysis).

We now analyze the results of decomposition for urban and rural Pakistan. The first interesting observation is that the relative position of eight of the thirteen consumption categories in terms of their concentration ratios relative to the Gini coefficient of household consumption in urban and rural Pakistan is the same as that of Pakistan overall. Specifically the concentration ratios of cereals and grains; other food items; apparel textile, footwear and personal effects; and fuel and lighting have remained lower than the overall Gini coefficients of household consumption. On the other hand, fixtures and furniture; transport, travel, and communication; education and professional expenditures; and miscellaneous expenditure are consumption groups whose concentration ratios are greater than the overall Gini coefficients of household consumption. 
A major difference in results across rural and urban Pakistan occurs with respect to house rent and housing expenses. As in the case of overall Pakistan overall, house rent and housing expenses in urban Pakistan have also remained more unequally distributed than aggregate consumption expenditure. In rural Pakistan, on the other hand, house rent and housing expenses have remained more equally distributed in the first year of analysis. However, with the development of the rural economy over time, housing costs in rural areas have also increased, especially because rural households by and large also look for the same kind of durability, comforts and amenities (such as formal construction, modern kitchen, laundry washrooms, cooling, heating, etc.) in their houses as are available in urban localities. This may have made housing a luxury consumption category in the rural community. Thus, the difference in the position of house rent and housing expenses with respect to its concentration ratio between urban and rural Pakistan has diminished over time.

Another difference between urban and rural Pakistan is in terms of healthcare expenses. Contrary to the pattern for Pakistan overall, expenditure on healthcare in rural Pakistan has been more unequally distributed than overall consumption expenditure throughout the period of analysis. This indicates adverse consequences for inequality in terms of the healthcare of household members in rural areas. On the other hand, the pattern observed for urban Pakistan is the same as that for Pakistan overall, i.e., a decline in inequality in healthcare expenditure relative to the inequality in overall consumption expenditure. This convergence can be attributed to the development of the economy and increasing awareness of the importance of healthcare as urban households gain better access to global media.

\section{Summary}

This paper shows that income distribution in Pakistan, as revealed by the Gini index of household consumption, has improved moderately over the 12-year period 1992/93 to 2004/05, especially during the last six years and in urban regions. The extent of inequality in food consumption has remained substantially less than that of nonfood consumption. An important implication of this expected result is that the practice of estimating the poverty line in Pakistan by dividing the food poverty line by food consumption share among households below the food poverty line tends to underestimate the extent of poverty. 
A decomposition analysis of consumption inequality shows that, at the country level, the concentration ratios of cereals and grains, other food items, apparel textile, footwear and personal effects, and fuel and lighting have remained lower than the overall Gini index of household consumption, indicating that these consumption components are classified as relative necessities. On the other hand, the concentration ratios of house rent and housing expenses, fixtures and furniture, transport, travel, and communication, education and professional expenditures, and miscellaneous expenditure have remained greater than the overall Gini index household consumption, implying that these consumption groups can be treated as relative luxuries.

The existing pattern of inequality in education expenditure indicates that poverty may be perpetuated among poor families both in rural and urban areas. In contrast, healthcare expenditure in urban areas has been distributed relatively more evenly in the most recent year considered with a sharp decline in the concentration ratio in 2004/05, implying that poor households are becoming more conscious of the health of their members. However, the level of inequality in health care expenditures in rural areas has remained persistent and somewhat higher than the level of inequality in overall consumption expenditure.

Another difference in results across rural and urban Pakistan is with respect to housing expenditure (house rent and housing expenses). While in urban areas housing expenditures have remained more unequally distributed compared to aggregate consumption expenditure, in rural areas housing expenditures were more equally distributed in the first year of analysis. However, with the development of the rural economy and blurring of the rural-urban divide over time, housing costs in rural areas have increased and rural households have also started looking for durability and comfort in the same way that urban households do, thereby making housing a luxury consumption category in the rural community as well. 


\section{References}

Adams, J. R. (1993). Non-Farm Income and Inequality in Rural Pakistan. Pakistan Development Review, 32, 1187-1198.

Deaton, A. (1997). The Analysis of Household Surveys: A Microeconometric Approach to Development Policy. World Bank, Washington DC.

Demoussis, M., and Mihalopoulos. (2001). Adult Equivalence Scales Revisited. Journal of Agricultural and Applied Economics, 33(1), 135-146.

Elteto and Havasi. (2002). Effects of Observation Unit and Scale of Equivalence on Income Inequality and Poverty. Szocioplogia Szemle, 4, 157-170.

Havinga, I. C. et al. (1989). Poverty in Pakistan: 1984-85. Pakistan Development Review, 28, 851-867.

Idrees, M. (2007). An Analysis of Income and Consumption Inequalities in Pakistan. (Doctoral Dissertation). Department of Economics, Quaid-i-Azam University, Islamabad.

Jafri, S. M. Y. (2002). Issues in Measuring Poverty. Center for Research and Poverty Reduction and Income Distribution: Islamabad.

Kakwani, N. (2003). Issues in Setting Absolute Poverty Lines. Poverty and Social Development Papers.

Kruijk, H. et al. (1985). Changes in Poverty and Income Inequality in Pakistan during the 1970s. Pakistan Development Review, 24, 407-422.

Kruijk, H. et al. (1986). Inequality in Four Provinces of Pakistan. Pakistan Development Review, 25, 685-706.

Kruijk, H. et al. (1987). Sources of Income Inequality in Pakistan. Pakistan Development Review, 26, 659-672.

Lichfield, J. A. (1999). Inequality Methods and Tools. World Bank, Washington DC.

Nasir, Z. M., \& Mahmood, R. (1998). Personal Earning Inequalities in Pakistan: Findings from HIES 1993-9, Pakistan Development Review, 37, 781-792. 
Rao, V. M. (1969). Two Decompositions of Concentration Ratio. Journal of the Royal Statistical Society, 132, 418-425.

Shorrocks, A. F. (1982). Inequality Decomposition by Factor Components. Econometrica, 50, 193-211. 